\title{
Model of semidiurnal pseudo tide in the high-latitude upper mesosphere
}

\author{
E. R. Talaat ${ }^{1}$ and H. G. Mayr ${ }^{2}$ \\ [1] \{Applied Physics Laboratory, Johns Hopkins University, Laurel, MD, USA\} \\ [2] \{Goddard Space Flight Center, Greenbelt, MD, USA\}
}

Accepted for Publication

In

Joumal of Atmospheric and Solar Terrestrial Physics

August 24, 2011 


\begin{abstract}
We present numerical results for the $\mathrm{m}=1$ meridional winds of semidiurnal oscillations in the high-latitude upper mesosphere, which are generated in the Numerical Spectral Model (NSM) without solar excitations of the tides. Identified with heuristic computer runs, the pseudo tides attain amplitudes that are, at times, as large as the non-migrating tides produced with standard solar forcing. Under the influence of parameterized gravity waves, the nonlinear NSM generates internal oscillations like the quasi-biennial oscillation, that are produced with periods favored by the dynamical properties of the system. The Coriolis force would favor at polar latitudes the excitation of the 12-hour periodicity. This oscillation may help explain the large non-migrating semidiurnal tides that are observed in the region with ground-based and satellite measurements.
\end{abstract}

\title{
1. Introduction
}

The semidiurnal tide is one of the largest dynamical features of the mesosphere and lower thermosphere. At mid- and high-latitudes, the semidiurnal amplitudes in winds and temperatures can exceed those of the diurnal tide (e.g. Burrage et al., 1995; Avery et al., 1989; Manson et al., 1989; Vincent et al., 1989; Jacobi et al., 1999). The migrating tides (i.e., sun-synchronous diurnal and semidiurnal oscillations) dominate. But the non-migrating tides are also found to be important in the region. Based on observations and supported by modeling studies, a large body of evidence has accumulated over the years that shows that the non-migrating tides represent a major part of the phenomenology that characterizes the mesosphere and lower thermosphere (e.g., Manson et al., 1989; Miyahara et al., 1999; Forbes et al., 1995; Talaat and Lieberman, 1999, 2010).

The phase progression of observed non-migrating tides suggests that they propagate up from below [e.g., Talaat and Lieberman, 1999]. However, the sources for these tides in the troposphere and stratosphere are not sufficient to reproduce the observed amplitudes in the mesosphere [e.g., Miyahara et al., 1993; Hagan et al., 1997]. Non-migrating tides are also generated through non-linear interactions between migrating tides and planetary waves (e.g., Teitelbaum and Vial, 1991; Forbes et al., 1995; Miyahara et al., 1997; Hagan and Roble, 2001), and Mayr et al. (2003, 2005) demonstrated that gravity wave interactions contribute significantly to the non-linear coupling involved.

We report here that the Numerical Spectral Model (NSM) produces, without solar excitation of tides, non-migrating semidiurnal tides in the upper mesosphere at highlatitudes - we refer to as pseudo tides. (This term was coined by Walterscheid et al. [1986] to describe a semidiurnal wave at high latitudes that was much larger than the migrating tide.) The present paper is the follow-on of a study of wind oscillations with periods around 10 hours, which have been observed with different measurement techniques in the upper mesosphere (e.g., Manson and Meek, 1990; Hernandez, 1992, 1993; Ruster and Sivjee, 1994; Forbes et al., 1999; Portnyagin, 2000; Wu et al., 2002). Lamb waves and "normal modes" were invoked to explain the measurements, but inertio gravity waves, nonlinear coupling between tides and planetary waves were also proposed as possible excitation mechanisms. Such oscillations are generated in the 
NSM with zonal wave numbers $m=0-2$ (Mayr et al., 2004). With periods around 10 hours, close to 12 hours, the waves have much in common with the semi-diurnal tide. Based on classical tidal theory (Longuett-Higgins, 1968), close examination shows that the oscillations are related to Class-I waves, which have also been referred to as Inertio Gravity Waves (Andrews et al., 1987; Volland, 1988). Since the waves occupy low zonal wave numbers, Mayr et al. refer to them as planetary-scale inertio gravity waves (PIGW). The PIGW are not produced in the NSM when the planetary waves (PW) are turned off. When the diurnal tides are turned off, the PIGW are still generated as shown in Fig. 1. In that case, the amplitudes (Fig. 1b) are comparable to those produced with tides (Fig. 1a), but the seasonal variations differ considerably.

We found that the PIGW spectrum without tidal excitation is highly variable and can broaden around 10 hours to produce 12-hour oscillations. As seen in the following model results for $\mathrm{m}=1$, the generated pseudo tides contribute significantly to the variability of the wind field to produce, at times, relatively large semidiurnal amplitudes in the upper mesosphere at high latitudes.

\section{Numerical Spectral Model}

The Numerical Spectral Model (NSM) extends from the Earth' surface into the thermosphere, and its design and applications have been discussed in the literature (e.g., Chan et al., 1995; Mengel et al., 1995; Mayr et al., 1997, 1998). For the zonal mean, the model is driven by solar heating due to ultraviolet radiation in the mesosphere and stratosphere taken from Strobel (1978). The tides are driven exclusively by the migrating thermal excitation sources in the troposphere and stratosphere (Forbes and Garret, 1978). Extreme ultraviolet heating is applied in the thermosphere based on the efficiency provided by Torr et al. (1980). Nonlinear interactions between migrating tides and planetary waves produce the non-migrating tides. The planetary waves are generated through the instabilities that arise in the zonal-mean temperature and wind fields. The radiative loss is described in terms of Newtonian cooling adopted from Zhu [1989].

An integral part of the NSM is that it incorporates the Doppler Spread Parameterization (DSP) for small-scale gravity waves (GWs) (Hines, 1997a, b). The DSP has also been applied successfully in a variety of other global-scale models (e.g., Akmaev, 2001a, b; Manzini et al., 1997) and has been discussed extensively in the literature.

In the NSM discussed here, tropospheric heating is applied for the zonal mean to reproduce qualitatively the observed zonal jets near the tropopause and the accompanying latitudinal temperature variations. This heat source generates through instabilities tropospheric planetary waves, in particular those for zonal wave numbers $m$ $=1,2$. To capture the GW effects and nonlinear interactions, the time step used in these runs is $5 \mathrm{~min}$. The data are recorded every hour, and a Fourier spectral analysis is performed in time (over 10,5 , or 3 day running windows) and longitude at each latitude and altitude to extract wave amplitude and phase. 


\section{Comparison of Pseudo Tide with Solar Non-migrating Tides}

Under the steady source of solar heating, the regular non-migrating tides reveal persistent seasonal variation. The present pseudo tide is solely generated by variable planetary waves, which are excited by instabilities and influenced by background zonal wind and temperature variations. The tide thus manifests itself mainly during relative short periods of time. This variability is apparent in the following model results that are analyzed and presented with variable running windows.

Figure $2 \mathrm{a}$ shows the maximum amplitude $\mathrm{m}=1$ spectra of meridional winds at $100 \mathrm{~km}$ for westward and eastward propagating waves, computed with standard excitation of the solar migrating tides. Periods between 8 and 14 hours are shown, and a Mercator projection is applied to expand the regions at high latitudes. The amplitudes are computed with running windows (RW) of 10 (a), 5 (b), and 3 (c) days (sliding every day) applied to a time span of 6 months after December solstice. In the Polar Regions, the 12-hour westward propagating non-migrating tide dominates, and the maximum amplitudes increase from 50 to $62 \mathrm{~m} / \mathrm{s}$ as the RW is lowered from 10 to 3 days. Also shown in the spectra are oscillations with periods around 10 hours, which have been identified as planetary-scale inertio gravity waves (PIGW) (Mayr et al., 2004) earlier discussed. As the RW is shortened, the amplitudes of the PIGW broaden and merge into the 12-hour semidiurnal tide.

The meridional wind spectra generated without excitation of the migrating tides are shown in Fig. 3, analogous to Fig. 2. As expected, and in contrast to Fig 2, the sharp spectral peaks of the non-migrating 12-hour tide are not generated. But there is considerable spectral power around 11 hours, which leaks into the 12-hour oscillation with wind amplitudes that increase from about 12 to $50 \mathrm{~m} / \mathrm{s}$ near the South Pole as the RW is shortened from 10 to 3 days. Figure 3 clearly shows that the semidiurnal oscillations generated without the solar tidal excitation are an important part of the nonmigrating tides in Fig. 2. Generated solely with planetary waves (PW) excited by instabilities, however, the spectrum of the semidiurnal pseudo tide is much more variable than that produced with the solar tide. That variability can produce, at times, relatively large semidiurnal amplitudes in the upper mesosphere.

In Figure 4 we examine the seasonal variations of the 12-hour westward propagating oscillations for $\mathrm{m}=1$ meridional winds at $100 \mathrm{~km}$, which are produced with tidal excitation. The model results are presented with $4-\mathrm{m} / \mathrm{s}$ contour intervals, and the lowest 2 levels are suppressed to eliminate clutter. As in Fig. 2 for the corresponding spectra, different running windows (RW) are applied, and the amplitudes are presented for the 3 rd model year from 24 to 36 months, varying with latitude and Mercator projection. (The spectral analyses for $m=1$ in Fig. 2 apply to the time span from 24 to 30 months and covers all the seasonal variations, albeit in both hemispheres.) As seen in Fig. 2 for the westward propagating oscillations, the semidiurnal tides peak in the Polar Regions. With tidal excitation, the peak amplitudes around $50 \mathrm{~m} / \mathrm{s}$ tend to occur during the fall and spring seasons, but considerable oscillations are also generated throughout the year including the summer and winter months.

Analogous to Fig. 4, we present in Figure 5 the seasonal variations generated without tidal excitation. They occur mainly around equinox during the spring and fall seasons in 
both hemispheres. With RW of 10 days (5b), the amplitudes are small, generally less than $15 \mathrm{~m} / \mathrm{s}$, compared to values around $50 \mathrm{~m} / \mathrm{s}$ with tidal excitation in Fig. $4 \mathrm{a}$. For the 5 -day window (5b) the amplitudes increase to $30 \mathrm{~m} / \mathrm{s}$, versus $60 \mathrm{~m} / \mathrm{s}$ in Fig. $4 \mathrm{~b}$. And with the 3-day RW (5c), the equinoctial maxima of the 12-hour pseudo tide have amplitude maxima around $50 \mathrm{~m} / \mathrm{s}$, which are comparable to the values generated with tidal excitation (Fig. 4c). Consistent with the spectral analysis in Fig. 3, the variable 12hour pseudo tide can produce relatively large oscillations in the upper mesosphere. During short periods of time in the spring and fall seasons, the pseudo tides (Figs. 5b and $5 \mathrm{c}$ ) thus contribute significantly to the large amplitudes that are generated in the semidiurnal wind field (Figs. $4 \mathrm{~b}$ and $4 \mathrm{c}$ ).

In Figure 6, we examine the phase relationship with altitude of the $\mathrm{m}=1$ meridional winds at $84^{\circ}$ South, which are computed with (6a) and without (6b) excitation of the migrating tides. The plot covers a period of 3 days during a time span after March of the 3 rd model year, when the 12-month pseudo tide has large amplitudes as seen in Fig. $5 \mathrm{c}$. (The contours appear rugged because the model results were recorded in $5-\mathrm{km}$ intervals.) For the run with solar forcing, with contours of $6 \mathrm{~m} / \mathrm{s}$, the oscillation velocities grow with altitude and attain values as large as $71 \mathrm{~m} / \mathrm{s}$ at $105 \mathrm{~km}$. The periods are around 12 hours, varying from day to day. In addition, the vertical structure also shows some variability in wavelength, which is generally $20-30 \mathrm{~km}$ at this high latitude. In comparison, the pseudo tide (Fig. 6b) attains a peak amplitude of $60 \mathrm{~m} / \mathrm{s}$ at $100 \mathrm{~km}$. The periods are close to 12 hours, and the vertical wavelengths are about $20 \mathrm{~km}$. Although the oscillations are not generated with solar heating, the waves have properties closely resembling semidiurnal tides. During the short time period depicted, the large oscillations in Fig. 6b contribute significantly to the variability of the velocity field (Fig. 6a) produced with standard excitation of the solar tides.

\section{Discussion and Conclusion}

The numerical results discussed are generated in the NSM with small-scale gravity waves (GW), applying Hines' Doppler spread parameterization (DSP). As shown from a numerical experiment presented in Fig. 3 of Mayr et al. (2011), the GWs amplify the diurnal tide and decrease its vertical wavelength. We believe that this wave source is playing a central role in exciting the $\mathrm{m}=1$ pseudo tide. Due to the positive nonlinear feedback associated with critical level absorption, oscillations can be generated with periods that are favoured by the internal dynamical properties of the system. An example for this mechanism is the quasi-biennial oscillation (QBO), whose period is controlled by the 2-year time constant for the eddy viscosity (e.g., Mayr et al., 2010). And in the present case of the semidiurnal pseudo tide at polar latitudes, the Coriolis force would favour the excitation of the 12-hour periodicity.

In general, ground-based observations have difficulty resolving the diurnal or semidiurnal field into non-migrating and migrating components due to insufficient geographic coverage. Measurements taken near the poles are the exception, since different sites and/or different viewing angles from a single site allow longitudinal variations to be quantified. As a result, ground-based observations have for years detected the presence of non-migrating tides in Antarctica (e.g., Hernandez, 1993; 
Forbes, 1995; Portnyagin et al., 1998) and Arctic (e.g., Wu et al. 2003; Murphy et al., 2006).

Recently, limura et al. [2009, 2010] examined the non-migrating semidiurnal tide over the Antarctica and Arctic respectively using data from TIMED/TIDI. The observed dominant non-migrating modes were found to be the westward propagating tides with $\mathrm{m}$ $=1$ (and $\mathrm{m}=3$ ). As shown in Figs. 3, 5, the $\mathrm{m}=1$ semidiurnal pseudo tides generated in the NSM would contribute significantly to the observed oscillations at high latitudes. (The TIDI data also show a sizable stationary $\mathrm{m}=0$ tide, but there is no such pseudo tide in the model.) Iimura et al. found that, as a function of latitude, the amplitude of the $\mathrm{m}=1$ tide increases towards the pole - and our simulations produce a similar morphology (Figs. 3, 5). Typically, the ground-based meteor wind observations show that the vertical wavelength of the $m=1$ semidiurnal tide is greater than $30 \mathrm{~km}$. In TIDI data, the vertical wavelength of the $m=1$ semidiurnal tide is observed to decrease from $\sim 40 \mathrm{~km}$ at $65^{\circ}$ to $20 \mathrm{~km}$ at the pole. In agreement with the observations, Fig. 6 shows that the wavelength of the model pseudo tide is also close to $20 \mathrm{~km}$ at high latitudes.

In the real world and in the present nonlinear model, the sources of the semidiurnal tide are co-mingled and do not produce simple additive effects. Notwithstanding this complexity, we have identified with heuristic computer runs an additional source of variability for the semidiurnal tide. The pseudo tide discussed would likely manifest itself at high latitudes, particularly during periods of enhanced planetary wave activity or during seasons with weak solar forcing of the semidiurnal tides.

\section{Acknowledgments}

This work was supported by National Science Foundation grants 0640864 and 0946902. The authors are indebted to a reviewer for critical and constructive comments that contributed significantly to improve the paper.

\section{References}

Akmaev, R.A., 2001a. Simulation of large-scale dynamics in the mesosphere and lower thermosphere with the Doppler-spread parameterization of gravity waves: 1 . implementation and zonal mean climatology, J. Geophys. Res., 106, 1193.

Akmaev, R.A., 2001b. Simulation of large-scale dynamics in the mesosphere and lower thermosphere with the Doppler-spread parameterization of gravity waves: 2 . eddy mixing and diurnal tide, J. Geophys. Res., 106, 1205-1213.

Avery, S.K., Vincent, R.A., Phillips, A., Manson, A.H., Fraser, G.R., 1989. High latitude tidal behavior in the mesosphere and lower thermosphere, J. Atm. Terr. Phys., 51, 595.

Burrage, M.D., Wu, D.L., Skinner, W.R., Ortland, D.A., Hays, P.B., 1995. Latitude and seasonal dependence of the semidiurnal tide observed by the high-resolution Doppler imager, J. Geophys. Res., 100, 11313.

Chan, K. L., Mayr, H.G., Mengel, J.G., Harris, I., 1995. A numerical spectral model for the mean zonal circulation and the tides in the middle and upper atmosphere, Geophys. Monogr., 87, 265.

Forbes, J.M., Garrett, H.B., 1978. Thermal excitation of atmospheric tides due to insolation absorption by $\mathrm{O}_{3}$ and $\mathrm{H}_{2} \mathrm{O}$, Geophys. Res. Lett., 5, 1013.

Forbes, J.M., 1995. Tidal and planetary waves, Geophys. Monogr., 87, 67. 
Forbes, J.M., Makarov, N.A., Portnyagin, Y.I., 1995. First results from the meteor radar at South Pole: A large 12-hour oscillation with zonal wave number one, Geophys. Res. Lett., 22, 3247.

Forbes, J.M., Palo, S.E., Zhang, X., Portnyagin, Y.I., Makarov, N.A., Merzlyakov, E.G., 1999. Lamb waves in the lower thermosphere: Observational evidence and global consequences, J. Geophys. Res., 104, 17107.

Hagan, M. E., Chang, J.L., Avery, S.K., 1997. Global-scale wave model estimates of non-migrating tidal effects, J. Geophys. Res., 102, 163493.

Hagan, M.E., Roble, R.G., 2001. Modeling diurnal tidal variability with the National Center for Atmospheric Research thermosphere-ionosphere-mesosphereelectrodynamics general circulation model, J. Geophys. Res., 106, 24,869-24,882.

Hernandez, G., Smith, R.W., Fraser, G.J., Jones, W. L., 1992. Large-scale waves in the upper mesosphere at Antarctic high-latitudes, Geophys. Res. Lett., 19, 1347.

Hernandez, G., R. Fraser, W., Smith, G.J., 1993. Mesospheric 12-hour oscillation near south pole Antarctica, Geophys. Res. Lett., 20, 1787, 1993.

Hines, C.O., 1997a. Doppler-spread parameterization of gravity-wave momentum deposition in the middle atmosphere, 1, basic formulation, J. Atmos. Solar Terr. Phys., 59, 371.

Hines, C.O., 1997b. Doppler-spread parameterization of gravity-wave momentum deposition in the middle atmosphere, 2 , broad and quasi monochromatic spectra, and implementation, J. Atmos. Solar Terr. Phys., 59, 387.

Iimura, H., Palo, S.E., Wu, Q. et al., 2009. Structure of the nonmigrating semidiurnal tide above Antarctica observed from the TIMED Doppler Interferometer, J. Geophys. Res., 114, D11102, doi:10.1029/2008JD010608.

Iimura, H., Fritts, D.C., Wu, Q., et al., 2010. Nonmigrating semidiurnal tide over the Arctic determined from TIMED Doppler Interferometer wind observations, J. Geophys. Res., 115, D06109, doi:10.1029/2009JD012733.

Jacobi, C., Portnyagin, Y.I., Solovjova, T. V., et al., 1999. Mesopause region semidiurnal tide over Europe as seen from ground-based wind measurements, Adv. Space Res., 24, 1545.

Manson, A.H., Meek, C.E., Teitelbaum, H., et al., 1989. Climatology of semidiurnal and diurnal tides in the middle atmosphere $(70-110 \mathrm{~km})$ at middle latitudes (40$55^{\circ}$ ), J. Atm. Terr. Phys., 51, 579.

Manzini, E., McFarlane, N.A., McLandress, C., 1997. Impact of the Doppler spread parameterization on the simulation of the middle atmosphere circulation using the MA/ECHQAM4 general circulation model, J. Geophys. Res., 102, 25751.

Miyahara, S., Miyoshi, Y., Yamashita, K., 1999. Variations of migrating and nonmigrating atmospheric tides simulated by a middle atmosphere general circulation model, Adv. Space Res., 24(11), 1549-1558.

Miyahara, S, Yoshida, Y., Miyoshi, Y., 1993. Dynamical coupling between the lower and upper atmosphere by tides and gravity waves, J. Atm. Terr. Phys., 55, 1039.

Mayr, H.G., Mengel, J.G., Hines, C.O., Chan, K.L., Arnold, N.F., Reddy, C.A., Porter, H.S., 1997. The gravity wave Doppler spread theory applied in a numerical spectral model of the middle atmosphere: I. model and global-scale seasonal variations, J. Geophys. Res., 102, 26,077. 
Mayr, H.G., Mengel, J.G., Chan, K.L., Porter, H.S., 1998. Seasonal variations of the diurnal tide induced by gravity wave filtering, Geophys. Res. Lett., 25, 943.

Mayr, H.G., Mengel, J.G., Talaat, E.R., Porter, H.S., Chan, K.L., 2003. Non-migrating diurnal tides generated with planetary waves in the mesosphere, Geophys. Res. Lett., 30, 1832.

Mayr, H.G., Mengel, J.G., Talaat, E.R., Porter, H.S., Chan, K.L., 2004. Properties of internal planetary-scale inertio gravity waves in the mesosphere, Ann. Geophys., 22, 3421.

Mayr, H.G., Mengel, J.G., Talaat, E.R., Porter, H.S., Chan, K.L., 2005. Mesospheric non-migrating tides generated with planetary waves: II. influence of gravity waves, J. Atm. Solar Terr. Phys., 67, 981.

Mayr, H.G., Mengel, J.G., Chan, K.L. Huang, F.T., 2010. Middle atmosphere dynamics with gravity wave interaction in the numerical spectral model: Zonal-mean variations, J. Atmos. Sol. Terr. Phys., 72, 807.

Mayr, H.G., Mengel, J.G., Chan, K.L. Huang, F.T., 2011. Middle atmosphere dynamics with gravity wave interaction in the numerical spectral model: Tides and planetary waves, J. Atmos. Sol. Terr. Phys., 73, 711.

Mengel, J.G., Mayr, H.G., Chan, K.L., Hines, C.O., Reddy, C.A., Arnold, N.F., Porter, H.S., 1995. Equatorial oscillations in the middle atmosphere generated by smallscale gravity waves, Geophys. Res. Lett., 22, 3027.

Miyahara, S., Miyoshi, Y, Yamashita, K., 1999. Variations of migrating and nonmigrating atmospheric tides simulated by a middle atmosphere general circulation model, Adv. Space Res., 24(11), 1549-1558.

Murphy, D.J., et al., 2006. A climatology of tides in the Antarctic mesosphere and lower thermosphere, J. Geophys. Res., 111, D23104, doi:19.1029/2005JA011128.

Portnyagin, Y.I., Forbes, J.M., Merzlyakov, E.G., Makarov, N.A., Palo, S.E, 2000. Intra-diurnal wind variations observed in the lower thermosphere over the South Pole, Ann. Geophys., 18, 547.

Portnyagin, Y.I., Forbes, J.M., Makarov, N.A., Merzlyakov, E.G., Palo, S.E., 1998. The summertime 12-h wind oscillation with zonal wavenumber $\mathrm{s}=1$ in the lower thermosphere over the South Pole, Ann. Geophys., 16, 828-837.

Strobel, D.F., 1978. Parameterization of atmospheric heating rate from 15 to $120 \mathrm{~km}$ due to $\mathrm{O} 2$ and $\mathrm{O} 3$ absorption of solar radiation, J. Geophys. Res., 83, 7963.

Talaat, E.R., Lieberman, R.S., 1999. Non-migrating diurnal tides in mesospheric and lower thermospheric winds and temperatures J. Atmos. Sci., 56, 4073.

Talaat, E.R., Lieberman, R.S., 2010. Direct observations of nonmigrating diurnal tides in the equatorial thermosphere, Geophys. Res. Let., 37, L04803, doi:10.1029/2009GL041845.

Teitelbaum, H., Vial, F., 1991. On tidal variability induced by nonlinear interaction with planetary waves, J. Geophys. Res., 96, 14,169-14,178.

Torr, M.R., Richards, P.G., Torr, D.G., 1980. A new determination of the ultraviolet heating efficiency of the thermosphere, J. Geophys. Res., 85, 6819.

Vincent, R.A., Tsuda, T., Kato, S., 1989. Asymmetries in atmospheric tidal structure, J. Atm. Terr. Phys., 51, 609. 
Walterscheid, R.L., Sivjee, G.G., Schubert, G. Hamwey, R.M., 1986. Large amplitude semi-diurnal temperature variations in the polar mesopause. Evidence of a pseudotide, Nature, 342, 347-349.

Wu, Q., Killeen, T.L., McEwen, D., Solomon, S.C., Guo, W., Sivjee, G.G., Reeves, J. M., 2002. Observation of the mesospheric and lower thermospheric 10-h wave in the northern polar region, J. Geophys. Res., 107, 1082.

Wu, Q., Killeen, T.L., Nozawa, S., McEwen, N., Guo, W., Solomon, S.C., 2003. Observations of mesospheric neutral wind 12-hour wave in the Northern Polar Cap, J. Atmos. Sol. Terr. Phys., 65, 971-978.

Zhu, X, 1989. Radiative cooling calculated by random band models with S-1-beta tailed distribution, J. Atmos. Sci., 46, 511. 


\section{Figure Captions}

Figure 1. Computed meridional wind amplitudes for $m=1$ westward and eastward propagating planetary-scale inertio gravity waves, which are produced in the NSM with periods between 9 and 10.5 hours at $100 \mathrm{~km}$. The oscillations are generated with (a) and without (b) the excitation of the solar migrating diurnal tides. The amplitudes are of comparable magnitude, but the seasonal variations differ considerably. (Figure are taken from Mayr et al., 2004)

Figure 2. Maximum amplitude spectra of meridional winds at $100 \mathrm{~km}$ for westward and eastward propagating $\mathrm{m}=1$ waves, computed with standard excitation of the solar migrating diurnal tides. Periods between 8 and 14 hours are shown, and the Mercator projection is applied to expand the regions at high latitudes. Westward waves are shaded orange, while eastward waves are blue. Amplitudes are computed with running windows of 10 (a), 5 (b), 3(c) days applied to a time span of 6 months after December solstice. As expected, the non-migrating 12-hour tide dominates, and the spectral amplitudes increase with decreasing windows.

Figure 3. Same as Figure 1 but computed without the solar excitation of the migrating diurnal tides. With decreasing windows, the amplitudes of the periods around 10 hours broaden and leak apparently into the 12-hour oscillation, to produce maximum westward wind amplitudes of 12 (a), 30 (b) and 47 (c) $\mathrm{m} / \mathrm{s}$. The pseudo tides thus become increasingly more important when compared with the non-migrating semidiurnal amplitudes in Fig. 2, which have amplitudes of 50 (a), 60 (b), and 65 (c) $\mathrm{m} / \mathrm{s}$.

Figure 4. Seasonal variations of westward propagating oscillations for $m=1$ meridional winds at $100 \mathrm{~km}$, which are produced with solar excitation of diurnal tides, applying running windows of 10 (a), 5 (b) and 3 (c) days as in Figure 2. The results are presented for the $3^{\text {rd }}$ model year from 24 to 36 months, and the Mercator projection is applied to expand the regions at high latitudes. With $4-\mathrm{m} / \mathrm{s}$ contour intervals, the lowest 2 levels are suppressed to eliminate clutter. Wind oscillations are generated throughout the year, but the largest amplitudes tend to develop during the spring and fall seasons in both hemispheres.

Figure 5. Same as Figure 4 but computed without the solar excitation of the migrating diurnal tides. The oscillations are generated only around the spring and fall seasons, and the maximum amplitudes increase with decreasing widows, i.e. 14 (a), 31 (b), 47 (c) $\mathrm{m} / \mathrm{s}$, in agreement with the varying spectra in Fig. 3. The pseudo tides thus contribute increasingly to the variability of the non-migrating tides in Fig. 4.

Figure 6. Meridional winds varying with altitude for $\mathrm{m}=1$ at $84^{\circ} \mathrm{South}$, positive/red and negative/blue $(6 \mathrm{~m} / \mathrm{s}$ contours $)$, computed with (a) and without (b) excitation of the migrating diurnal tides. The oscillations cover a short period of 3 days during a time span after March of the $3^{\text {rd }}$ model year when the 12 -hour pseudo tide has large amplitudes as seen in Fig. $5 \mathrm{c}$. 

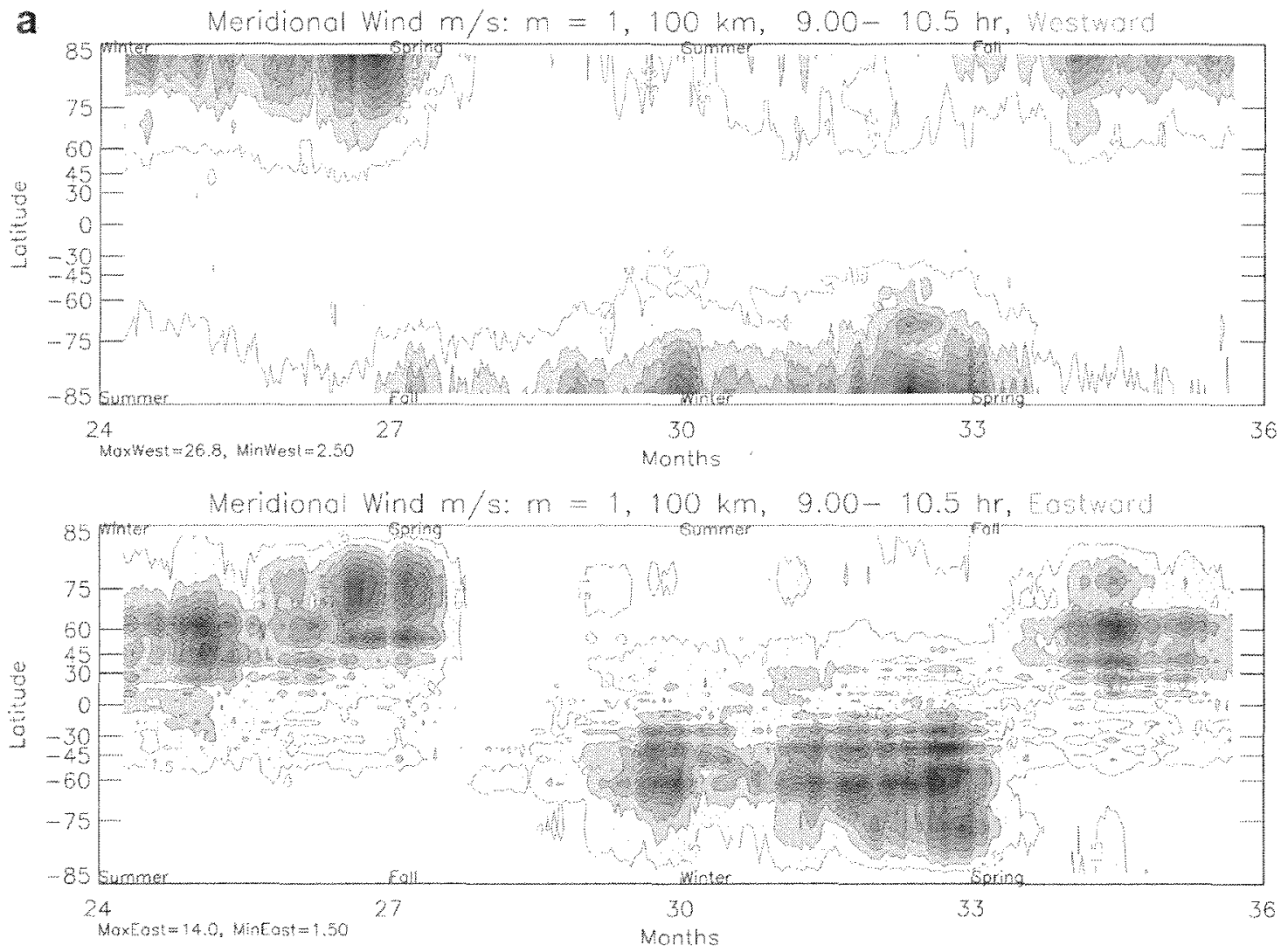

b

Without Excitation of Migrating Diurnal Tides
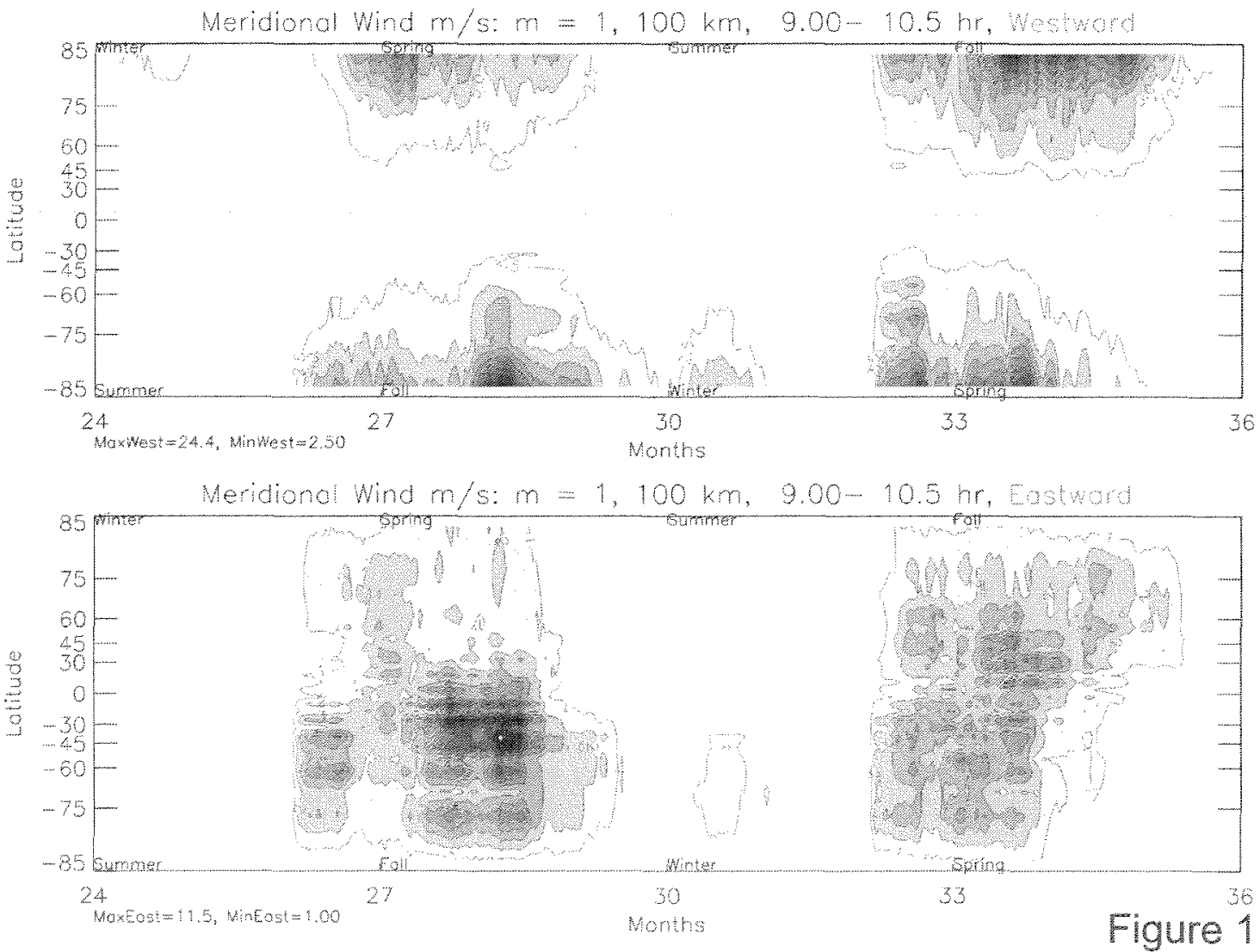

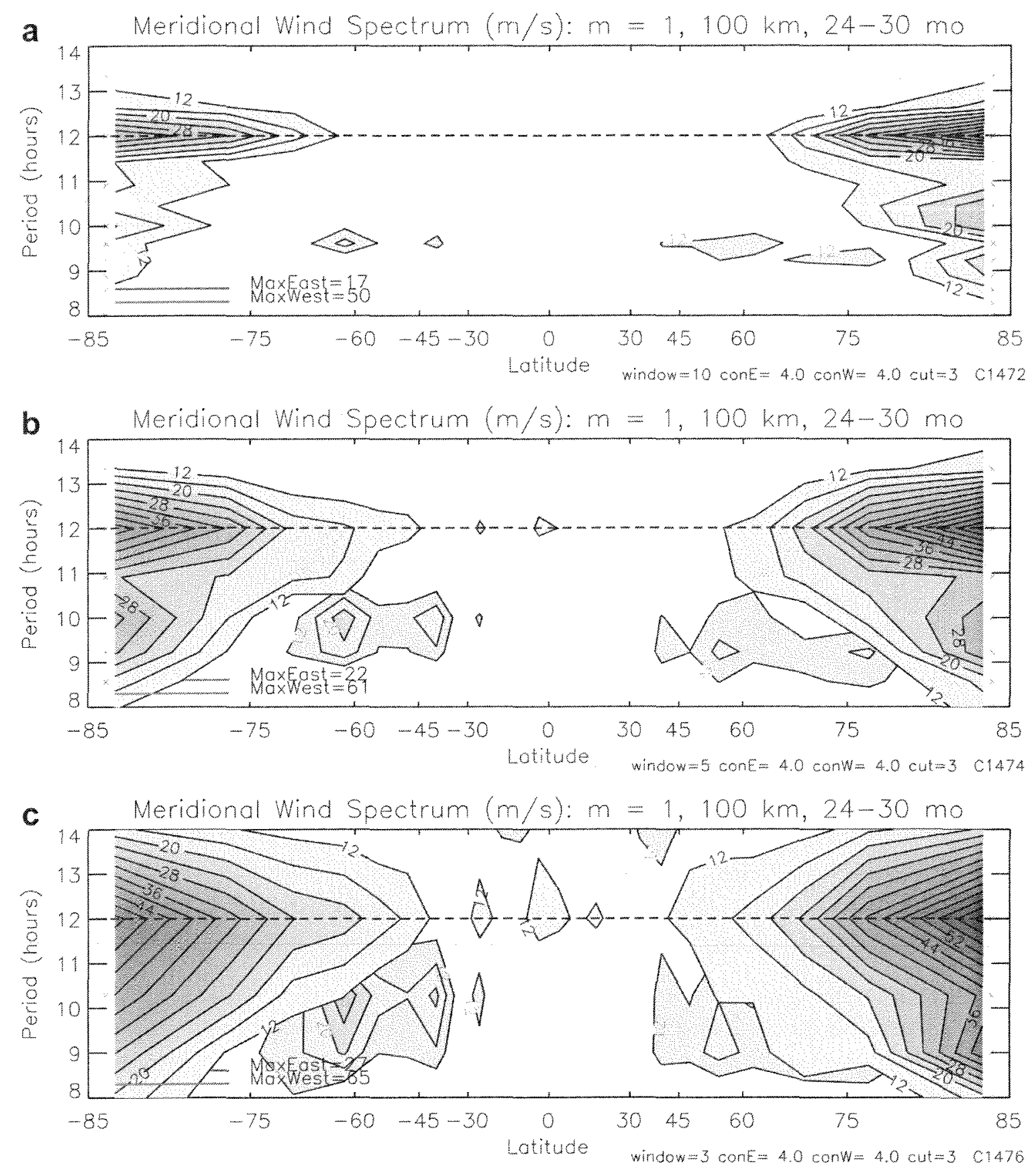

Figure 2 

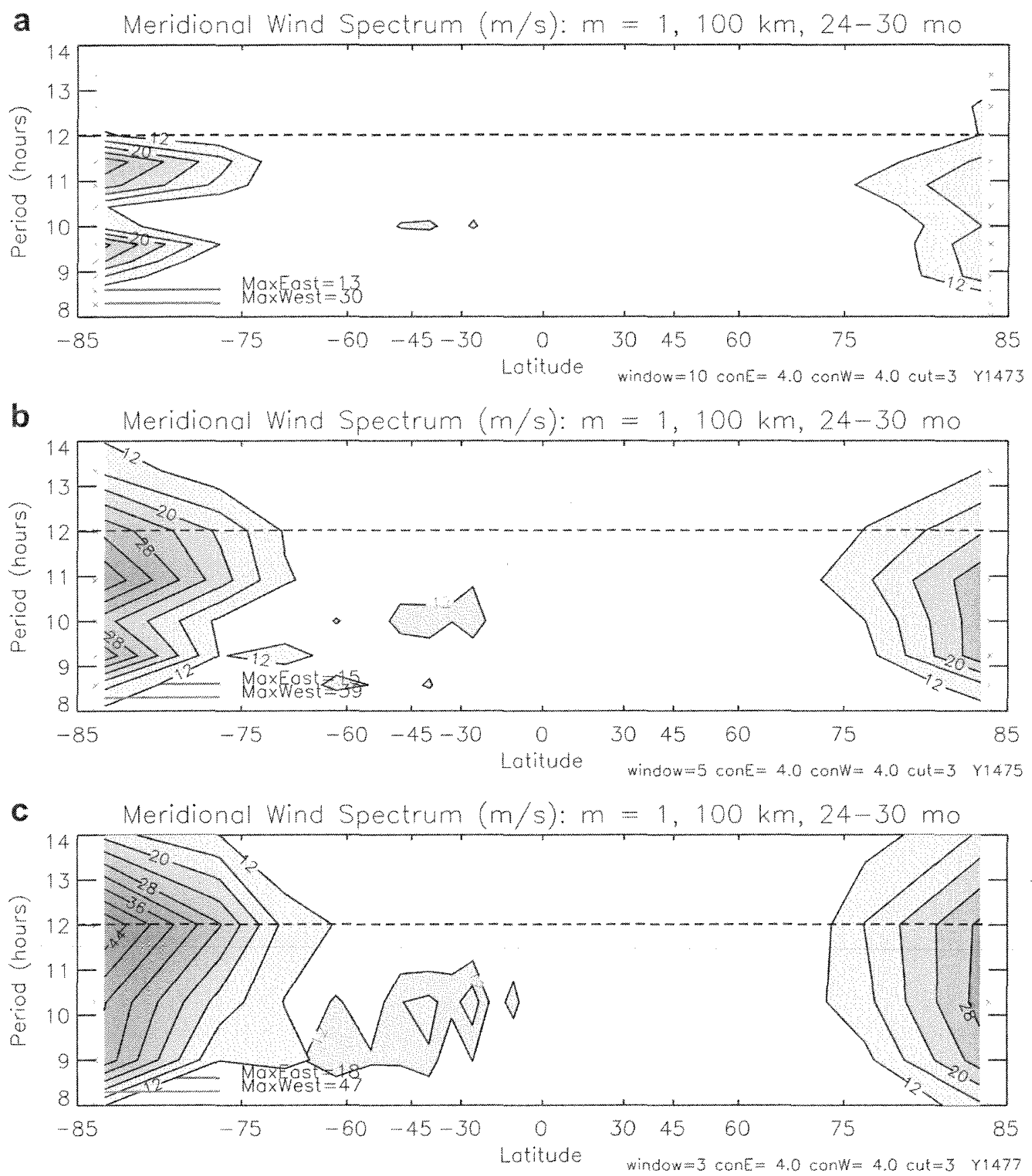

Figure 3 

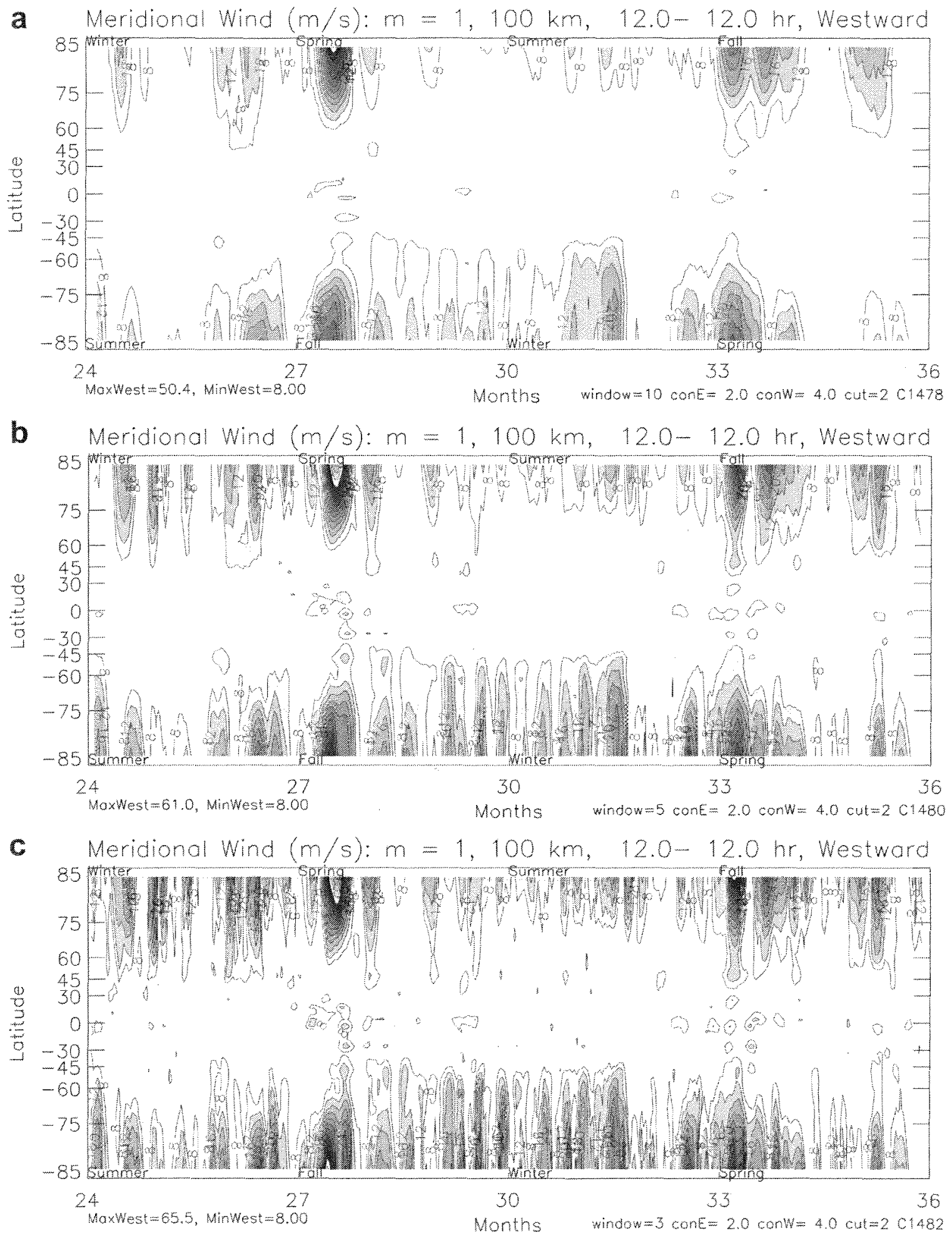

Figure 4 

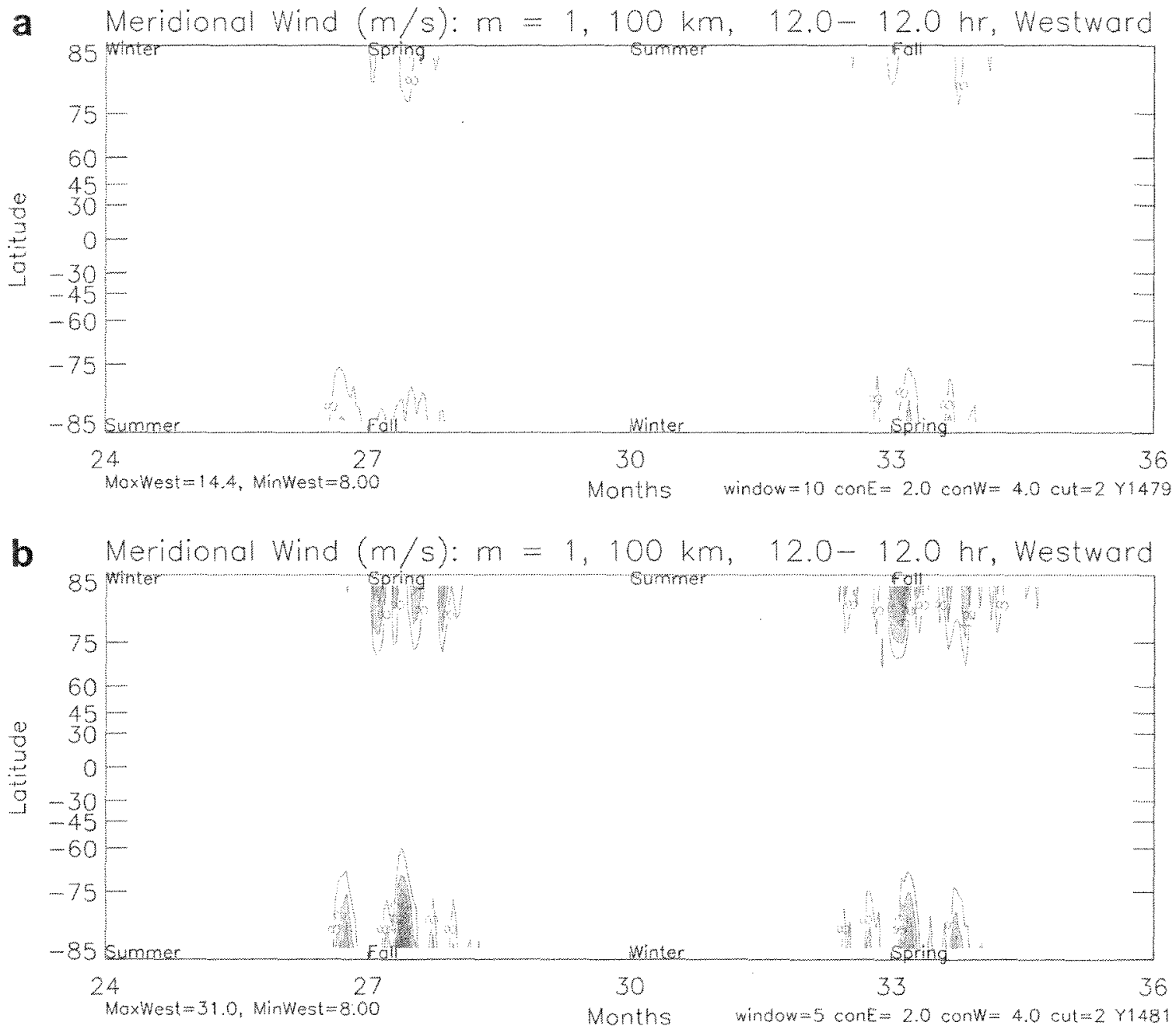

c Meridional Wind $(\mathrm{m} / \mathrm{s}): m=1,100 \mathrm{~km}, 12.0-12.0 \mathrm{hr}$. Westward

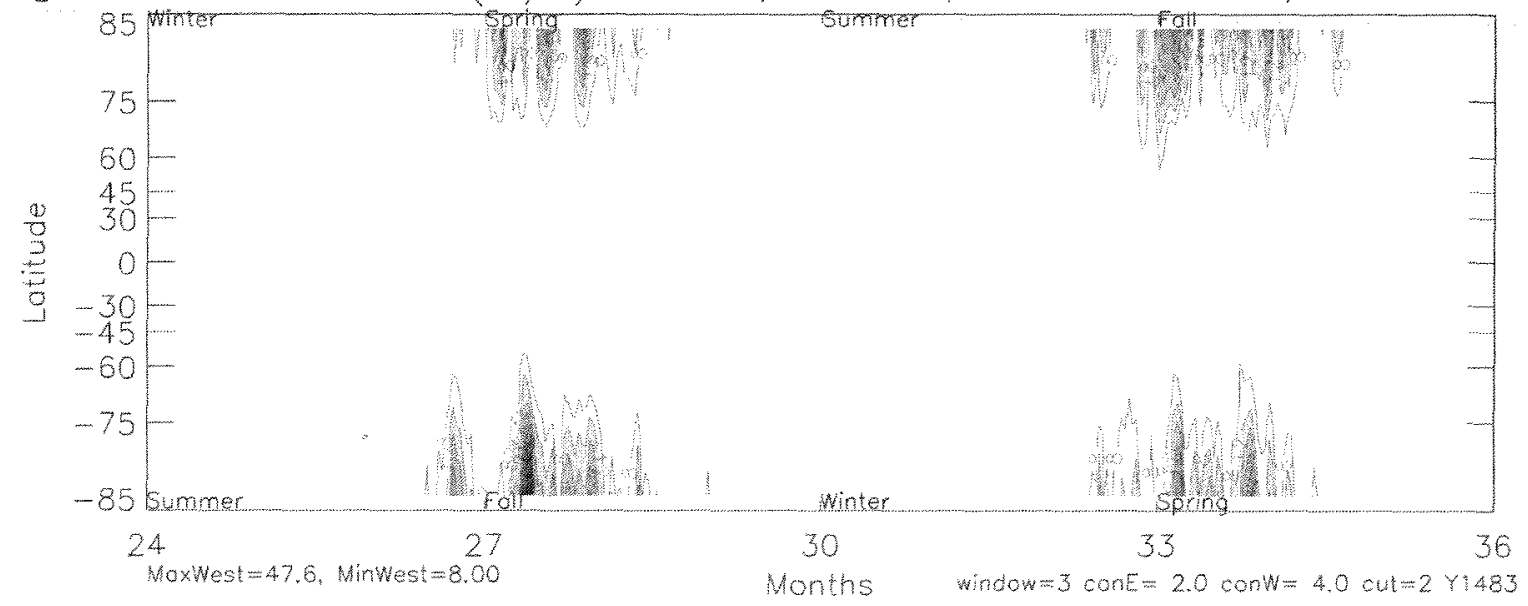

Figure 5 

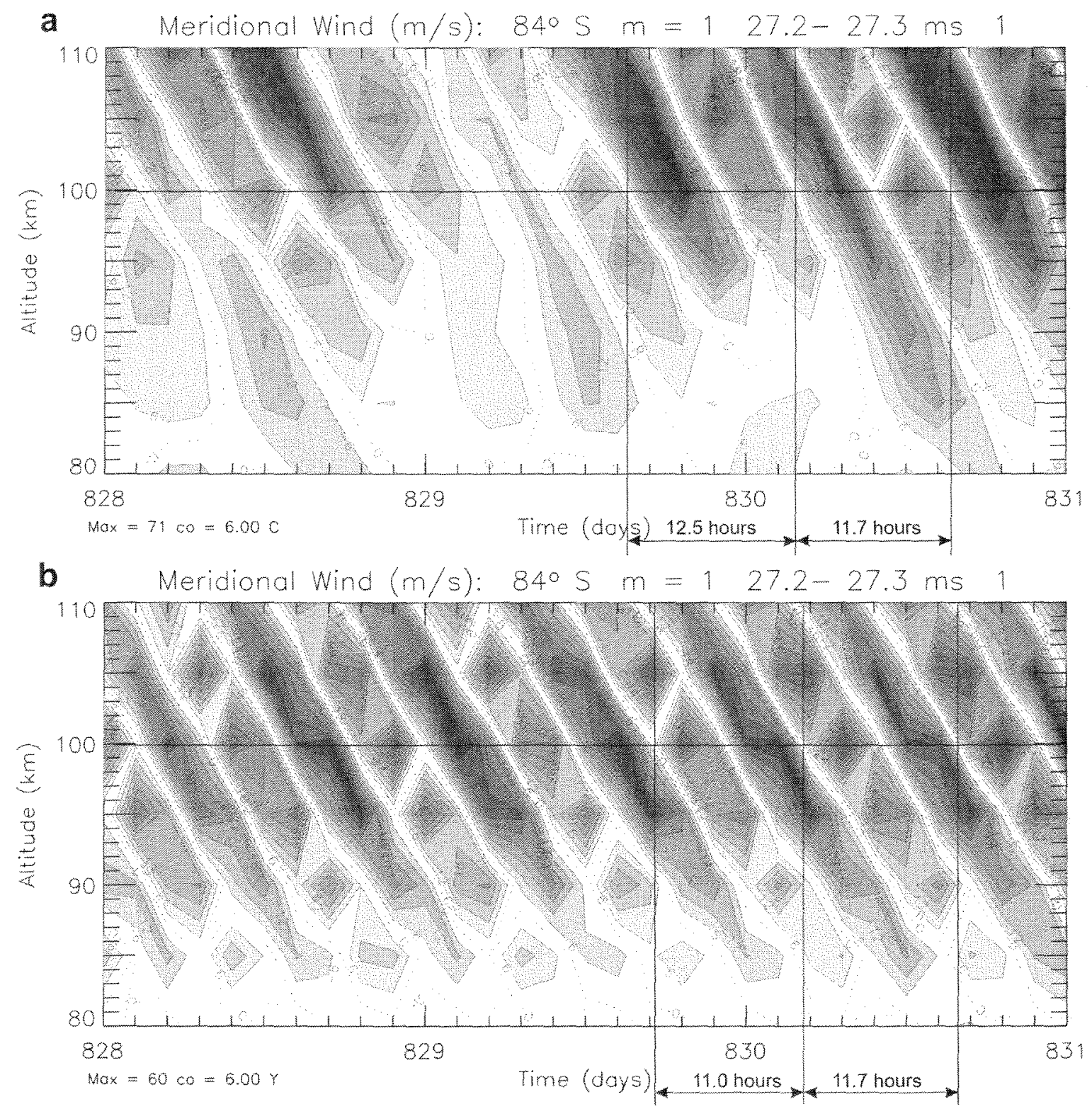

Figure 6 